\title{
Strategies for patient profiling in articular cartilage repair of the knee: a prospective cohort of patients treated by one experienced cartilage surgeon
}

\author{
Tommy S. de Windt • Sebastian Concaro • \\ Anders Lindahl • Daniel B. F. Saris • \\ Mats Brittberg
}

Received: 15 August 2011/Accepted: 18 December 2011/Published online: 14 January 2012

(C) The Author(s) 2012. This article is published with open access at Springerlink.com

\begin{abstract}
Purpose The purpose of this study was to report on the clinical outcome of a large heterogenic cartilage repair population treated with the profiling strategies of one experienced cartilage surgeon to provide evidence based tools for treatment selection in a clinical environment.

Methods A total of 216 patients were identified in this prospective single-surgeon study. For the primary and secondary treatment of smaller defects, microfracture (MF)
\end{abstract}

T. S. de Windt $(\bowtie) \cdot$ D. B. F. Saris

Department of Orthopaedics, University Medical Centre Utrecht, Utrecht, The Netherlands

e-mail: t.s.dewindt@umcutrecht.nl

D. B. F. Saris

e-mail: d.saris@umcutrecht.nl

S. Concaro

Department of Orthopaedics, Kungälvs Hospital, Kungälv, Sweden

e-mail: sebastian.concaro@gmail.com

\section{A. Lindahl}

Department of Clinical Chemistry and Transfusion Medicine, Institute of Laboratory Medicine, Sahlgrenska Academy at Gothenburg University, Sahlgrenska University Hospital,

Göteborg, Sweden

e-mail: anders.lindahl@clinchem.gu.se

\section{B. F. Saris}

Reconstructive Medicine, MIRA Institute for Technical Medicine \& Biomedical Engineering, University of Twente, Enschede, The Netherlands

\section{Brittberg}

Cartilage Research Unit, University of Gothenburg, Region

Halland Orthopaedics, Hallands Hospital Kungsbacka,

Kungsbacka, Sweden

e-mail: mats.brittberg@telia.com was used. Hyalograft $\mathrm{C}$ was used for first and second line larger defects, while carbon-fiber rod and pad implantations were used as a salvage procedure.

Results Three years after the initial procedure, the clinical improvement was excellent for MF and Hyalograft $\mathrm{C}$ $(P<0.001)$ and good for carbon-fiber procedures $(P<0.05)$. Hyalograft $\mathrm{C}$ patients with prior anterior cruciate ligament reconstruction had less clinical improvement $(P<0.05)$, while MF patients with prior cartilage repair were more likely to fail (Odds Ratio 20.5, $P<0.05$ ).

Conclusion This is the first study that provides an assessment of the treatment strategies used by an experienced cartilage surgeon. A treatment algorithm for cartilage repair in a heterogenic population was created that based on the findings of this study could be implemented in a clinical environment.

Level of evidence Prospective clinical case series, Level IV

Keywords Cartilage repair - Patient profiling · Experienced cartilage surgeon $\cdot$ Heterogenic population

\section{Introduction}

The steady increase in interest and availability of focal articular cartilage repair techniques and the good long-term results achieved during the last decade have increased the heterogeneity of the patients requiring cartilage repair $[5,8$, $39,40]$. That is, inclusion criteria for cartilage repair now range from single defects in young and active patients to early arthritic lesions in older (active) patients.

Although the focus on patient profiling has increased in recent years, treatment selection is still largely based on the preference of the surgeon and availability of different 
treatment types. Most surgeons agree that microfracture (MF) is a good option for smaller defects, while autologous chondrocyte implantation (ACI) is preferred for larger lesions [3]. The clinical outcome seems dependent on the patient's age, level of activity, defect location and treatment delay $[3,12,19,25,43]$. It is important to note that these findings are based on studies that have excluded certain patients, despite them being suitable for articular cartilage repair procedures, as most (randomized) trials have strict inclusion criteria such as a maximum age or number of defects $[1,18,21,44,48,49]$. Only a handful of studies include salvage procedures for (young) patients with early osteoarthritic lesions [29]. Moreover, it has been shown that the methodological quality of studies in cartilage repair is generally low [20]. As such, there is a need for an evidence based selection procedure to identify patients suitable for focal cartilage repair.

The purpose of this prospective study was to analyze the clinical outcome of patients following the application of extensive profiling strategies, by an experienced cartilage surgeon (MB), to a heterogenic group of patients suitable for cartilage repair to provide evidence based tools for treatment selection in a clinical environment.

\section{Materials and Methods}

Between 2006 and 2008, two hundred and sixteen patients suitable for focal cartilage repair were followed in this prospective study. The inclusion criteria for the study were: traumatic or degenerative symptomatic full thickness grade III to IV International Cartilage Repair Society lesions (ICRS) $[9,35]$ on the femur, trochlea and patella. The most important indicators for treatment were pain in rest and motion and (occasional) locking of the joint. In addition, a baseline Brittberg-Peterson VAS $\geq 50$ contributed strongly to the decision for surgery. Patients were excluded from the study if they had multiple defects in one knee that were treated with different techniques, e.g. MF and ACI and/or opening wedge osteotomy, symptomatic cartilage or ligament injuries in both knees, widespread osteoarthritis, inflammatory arhtritis and/or incomplete baseline questionnaires ( $>3$ missing items per questionnaire). During the initial screening, several patient characteristics such as age, BMI, smoking, defect size, defect location, defect cause, symptom to treatment delay and previous procedures, as well as baseline outcome were recorded in a database. All patients gave their informed consent prior to inclusion in this study. A senior surgeon (MB) in a specialized cartilage repair centre treated all patients.

\section{Treatment strategy and surgical techniques}

For the first and second line (subsequent to previous repair) treatment of smaller defects $\left(\leq 2.5 \mathrm{~cm}^{2}\right), \mathrm{MF}$ as described by Steadman was used [47]. Hyalograft C autografts [38] were used for the first and second line treatment of larger defects $\left(>2.5 \mathrm{~cm}^{2}\right)$ while carbon-fiber scaffold implantation was used as a salvage procedure for medium to large $\left(\geq 1.5 \mathrm{~cm}^{2}\right)$ early osteoarthritic (ICRS grade III-IV) defects. In addition, MF and carbon-fiber scaffolds were used for partial graft repair (i.e. repair of a failure of up to one-third of a previous created autologous chondrocyte graft). The Hyalograft $\mathrm{C}$ technique was preferred over MF for patients with high (sport related) physical demands with lesions $1.5-2 \mathrm{~cm}^{2}$ as well as patients with more than two previous cartilage repair procedures. Figure 1 provides an overview of the predefined treatment algorithm used in this study.

After drilling down to the vascular subchondral bone, woven carbon-fiber scaffolds were implanted as rods for convex surfaces and pads for concave surfaces $[4,7,27$, 33]. A Hyalograft $C$ implantation for all femoral and trochlear defects was performed with arthroscopy, whereas
Fig. 1 Treatment algorithm with pain, lesion type, defect size and patient activity as indicators for treatment selection. *International Cartilage Repair Society

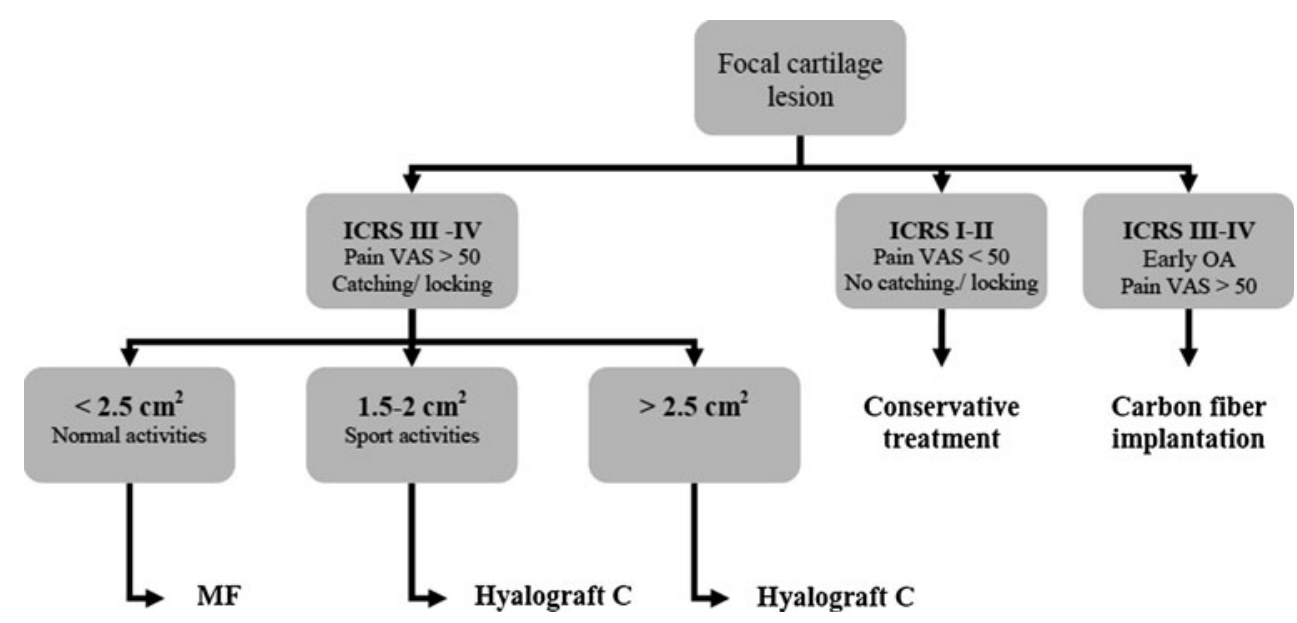


mini-arthrotomy was used for patellar lesions. A treatment was considered a failure if during a second look arthroscopy, a patient needed a new repair procedure for at least two-thirds of the cartilage defect.

\section{Rehabilitation}

All patients were weight bearing immediately after surgery, walking with crutches for 4- to 6-weeks to the extent allowed by an individual's pain tolerance. Patients with larger defects $\left(>2 \mathrm{~cm}^{2}\right)$ and all patients treated with Hyalograft $\mathrm{C}$ received an additional knee brace that was locked in extension for 2-weeks and unlocked for 4-weeks. Each patient trained once to twice daily under supervision of a specialized physiotherapist for 6-weeks and selftraining exercises were recommended for further 6-weeks. Return to full activity was not permitted until at least 6-months post-operatively, depending on an individual's clinical improvement.

\section{Outcome measurement}

Patients were asked to complete four patient-based questionnaires: the Knee Injury and Osteoarthritis Outcome Score (KOOS), the Brittberg-Peterson Visual Analogue Scale (VAS), the Lysholm Knee Scoring Scale and a subjective evaluation of clinical improvement (SECI) prior to and 3 years after surgery. The KOOS was designed for the follow-up of knee injury and osteoarthritis and has been validated for the treatment of cartilage lesions [2, 3, 41]. A modified version of the Lysholm scale has been validated to assess cartilage damage [45]. The Brittberg-Peterson VAS contains 13 items to measure different parameters of pain and function, on a scale of 0-100, where a score of 100 indicates the worst outcome [39]. The SECI consisted of a question regarding post-operative improvement (completely improved/much better/slightly improved/unchanged or worse) [6].

\section{Statistical analysis}

Paired 2-tailed $t$ tests were used to measure the improvement from baseline scores for each treatment type. Unpaired 2-tailed $t$ tests were used to compare the clinical outcomes between different treatment types.

For each separate treatment, as well as for all procedures, multiple linear regression analysis with backward elimination was used to determine prognostic factors that influenced the clinical outcome. To identify what influence the location of the defect had, the medial femoral condyle and patella were compared to all other sites. The defect cause was included in the analysis as either traumatic or non-traumatic. To ensure valid inclusion in the regression model, each patient's characteristics were subjected to a normality test using the Kolmogorov-Smirnov coefficient, a test for inter-variable correlation with the Pearson correlation coefficient and the variance inflation factor (VIF) and a test for autocorrelation with the Durbin-Watson coefficient. A VIF close to zero is considered indicative for multicollinearity [10]. A Durbin-Watson coefficient close to zero or four suggests strong negative and strong positive autocorrelation respectively [13]. Characteristics that were not normally distributed were excluded from the regression analysis. To exclude a possible treatment-bycovariate effect between the treatment types and the patient characteristics, a Levene homogeneity test was used. For each characteristic, the regression coefficient (B) along with the $P$ value and $95 \%$ confidence interval (CI) was obtained. The $B$ coefficient indicated the change in clinical outcome score for the presence or alteration of an included variable. Multiple logistic regression analysis was used to identify risk factors for failure after treatment and determine their separate odds ratios, along with the $P$ values and 95\% CI's [11]. Statistical analysis was performed with SPSS 17.0. $P$ values $<0.05$ were considered statistically significant.

\section{Results}

Of the 216 patients, 86 patients were treated with MF, 71 with Hyalograft $\mathrm{C}$ and 59 with carbon-fiber scaffolds. For MF, 10 patients had incomplete baseline questionnaires and 11 patients were lost to follow-up. For Hyalograft C, 17 patients were excluded (incomplete: $n=6$, lost to followup: $n=11$ ). For carbon-fiber scaffolds, 12 patients were excluded (incomplete: $n=2$, lost to follow-up: $n=10$ ). From the resulting 166 patients, three separate cohorts were obtained: 65 patients were treated with MF; 54 with Hyalograft $\mathrm{C}$ and 47 with carbon-fiber scaffolds. Table 1 summarizes the demographics and baseline characteristics.

\section{Clinical assessment}

The average follow-up time for MF, Hyalograft $\mathrm{C}$ and carbon-fiber scaffolds was $38 \pm 5$ months, $36 \pm 8$ months and $36 \pm 6$ months, respectively. The baseline scores were comparable for MF and Hyalograft $\mathrm{C}$ (n.s.) and slightly (0-4 points) lower for carbon-fiber scaffolds $(-8$ points in the Lysholm score $(P=0.003)$. (Table 1$)$ Statistically significant pre- to post-operative improvement was seen for all scores of the MF and Hyalograft $\mathrm{C}$ groups. $(P<0.001)$ For carbon-fiber-scaffolds the clinical improvement was good. $(P<0.001-0.002)$ The improvement from baseline was higher for both the MF and Hyalograft $\mathrm{C}$ cohorts, compared to carbon-fiber scaffolds and statistically 
Table 1 Demographics and baseline characteristics

\begin{tabular}{|c|c|c|c|}
\hline Characteristic & Microfracture $(n=65)$ & Hyalograft C $(n=54)$ & Carbon fiber $(n=47)$ \\
\hline Age (mean years \pm SD) & $40 \pm 12$ & $37 \pm 9$ & $47 \pm 9$ \\
\hline Men & $54 \%$ & $63 \%$ & $62 \%$ \\
\hline $\mathrm{BMI}($ mean $\pm \mathrm{SD})$ & $26.2 \pm 4.3$ & $25.3 \pm 3.6$ & $26.5 \pm 5.5$ \\
\hline Smoking $(n)$ & 10 & 5 & 7 \\
\hline Multiple defects $(n)$ & 16 & 25 & 16 \\
\hline Defect size $\left(\right.$ mean $\left.\mathrm{cm}^{2} \pm \mathrm{SD}\right)$ & $1.8 \pm 1.5$ & $3.9 \pm 2.3$ & $2.7 \pm 1.9$ \\
\hline Location: medial $(n)$ & 28 & 13 & 27 \\
\hline Lateral $(n)$ & 10 & 2 & 3 \\
\hline Trochlea $(n)$ & 8 & 6 & 2 \\
\hline Patella $(n)$ & 3 & 10 & 1 \\
\hline Femur and trochlea $(n)$ & 12 & 14 & 12 \\
\hline Femur and patella $(n)$ & 3 & 3 & 1 \\
\hline Trochlea and patella $(n)$ & 1 & 6 & 1 \\
\hline Sports-related injury & $65 \%$ & $52 \%$ & $68 \%$ \\
\hline Treatment delay (months \pm SD) & $97 \pm 100$ & $79 \pm 62$ & $100 \pm 85$ \\
\hline Second line treatment & $35 \%$ & $41 \%$ & $72 \%$ \\
\hline Diagnostic arthroscopy $(n)$ & 42 & 23 & 13 \\
\hline Previous treatment microfracture $(n)$ & 12 & 13 & 7 \\
\hline Previous treatment carbon fibers $(n)$ & 5 & 3 & 19 \\
\hline Previous treatment ACI $(n)$ & 6 & 6 & 8 \\
\hline Prior ACL reconstruction $(n)$ & 7 & 11 & 6 \\
\hline Time from ACL reconstruction ${ }^{\mathrm{a}}$ (months) & $66 \pm 89$ & $51 \pm 48$ & $144 \pm 36$ \\
\hline Baseline VAS (mean \pm SD) & $51.9 \pm 19.4$ & $56.1 \pm 19.7$ & $55.5 \pm 18.1$ \\
\hline Baseline overall KOOS (mean $\pm \mathrm{SD}$ ) & $47.8 \pm 15.4$ & $46.3 \pm 17.6$ & $45.2 \pm 17.2$ \\
\hline Baseline Lysholm ${ }^{\mathrm{b}}$ & $52.5 \pm 18.2$ & $51.6 \pm 21.8$ & $44.3 \pm 18.6$ \\
\hline Partial menisectomy $(n)$ & 20 & 10 & 18 \\
\hline Total menisectomy $(n)$ & 5 & 7 & 2 \\
\hline Partial (1/3) graft repair $(n)$ & 10 & 0 & 18 \\
\hline Opening wedge osteotomy $(n)$ & 5 & 5 & 7 \\
\hline Follow up (months \pm SD) & $34.0 \pm 5$ & $30.0 \pm 8$ & $32.0 \pm 6$ \\
\hline Failures $(n)$ & 8 & 8 & 7 \\
\hline Time to treatment failure (months \pm SD) & $17.0 \pm 6.8$ & $10.6 \pm 4.7$ & $17.1 \pm 4.8$ \\
\hline
\end{tabular}

$A C L$ anterior cruciate ligament, VAS Brittberg Petersson visual analogue scale, KOOS knee injury and osteoarthritis outcome score

a Time between ACL reconstruction and cartilage repair

b Tegner Lysholm Knee Scoring Scale

significant for the KOOS sports and QoL subscales. $(P<0.05)$ The clinical improvement for all scores and subscales is shown in Table 2 and Fig. 2. The SECI score was good with slight to complete improvement reported in $82 \%$ of $\mathrm{MF}$ procedures, $88 \%$ of Hyalograft $\mathrm{C}$ implantation and $80 \%$ for carbon-fiber procedures respectively. For all procedures, patients with anterior cruciate ligament (ACL) reconstruction improved on the KOOS and VAS $(P<0.05)$ but did not show a significant improvement in their Lysholm score (n.s.).
Linear regression analysis

Of the patient characteristics, smoking and treatment delay had to be excluded from analysis due to failed normality tests (n.s.). For the remaining variables, no multicollinearity or autocorrelation was observed in any of the treatment types (VIF 1.000-1.127, Durbin Watson 1.997-2.232). The Levene tests of homogeneity of regression slopes were not statistically significant (n.s.) indicating no treatment by covariate interaction. 
Table 2 Mean improvement from baseline in the Knee Injury and Osteoarthritis Outcome Score (KOOS), Brittberg-Peterson Visual Analogue Scale (VAS) and Lysholm Knee Scoring Scale 3 years after surgery

\begin{tabular}{|c|c|c|c|c|c|c|c|}
\hline \multicolumn{2}{|c|}{ Outcome scores } & \multicolumn{2}{|l|}{ Microfracture } & \multicolumn{2}{|l|}{ Hyalograft C } & \multicolumn{2}{|l|}{ Carbon fiber } \\
\hline & & Score \pm SD & $P$ value & Score \pm SD & $P$ value & Score \pm SD & $P$ value \\
\hline \multicolumn{2}{|l|}{ VAS } & $19 \pm 33$ & $<0.001$ & $25 \pm 26$ & $<0.001$ & $17 \pm 18$ & $<0.001$ \\
\hline KOOS & Symptoms & $20 \pm 21$ & $<0.001$ & $17 \pm 23$ & $<0.001$ & $12 \pm 24$ & 0.003 \\
\hline KOOS & Pain & $23 \pm 23$ & $<0.001$ & $23 \pm 26$ & $<0.001$ & $12 \pm 21$ & 0.001 \\
\hline KOOS & $\mathrm{ADL}$ & $19 \pm 20$ & $<0.001$ & $19 \pm 23$ & $<0.001$ & $10 \pm 20$ & 0.004 \\
\hline KOOS & Sports & $22 \pm 29$ & $<0.001$ & $18 \pm 26$ & $<0.001$ & $9 \pm 31$ & n.s. \\
\hline KOOS & QoL & $22 \pm 24$ & $<0.001$ & $23 \pm 25$ & $<0.001$ & $13 \pm 23$ & 0.001 \\
\hline KOOS & Total & $21 \pm 20$ & $<0.001$ & $20 \pm 21$ & $<0.001$ & $11 \pm 20$ & 0.002 \\
\hline \multicolumn{2}{|l|}{ Lysholm } & $15 \pm 22$ & $<0.001$ & $18 \pm 24$ & $<0.001$ & $13 \pm 18$ & $<0.001$ \\
\hline
\end{tabular}

$S D$ standard deviation

Fig. 2 Mean improvement from baseline and $95 \%$ Confidence intervals for the knee injury and osteoarthritis outcome Score (KOOS), the Brittberg-Peterson visual analogue scale (VAS) and the Lysholm Knee Scoring Scale 3 years after surgery

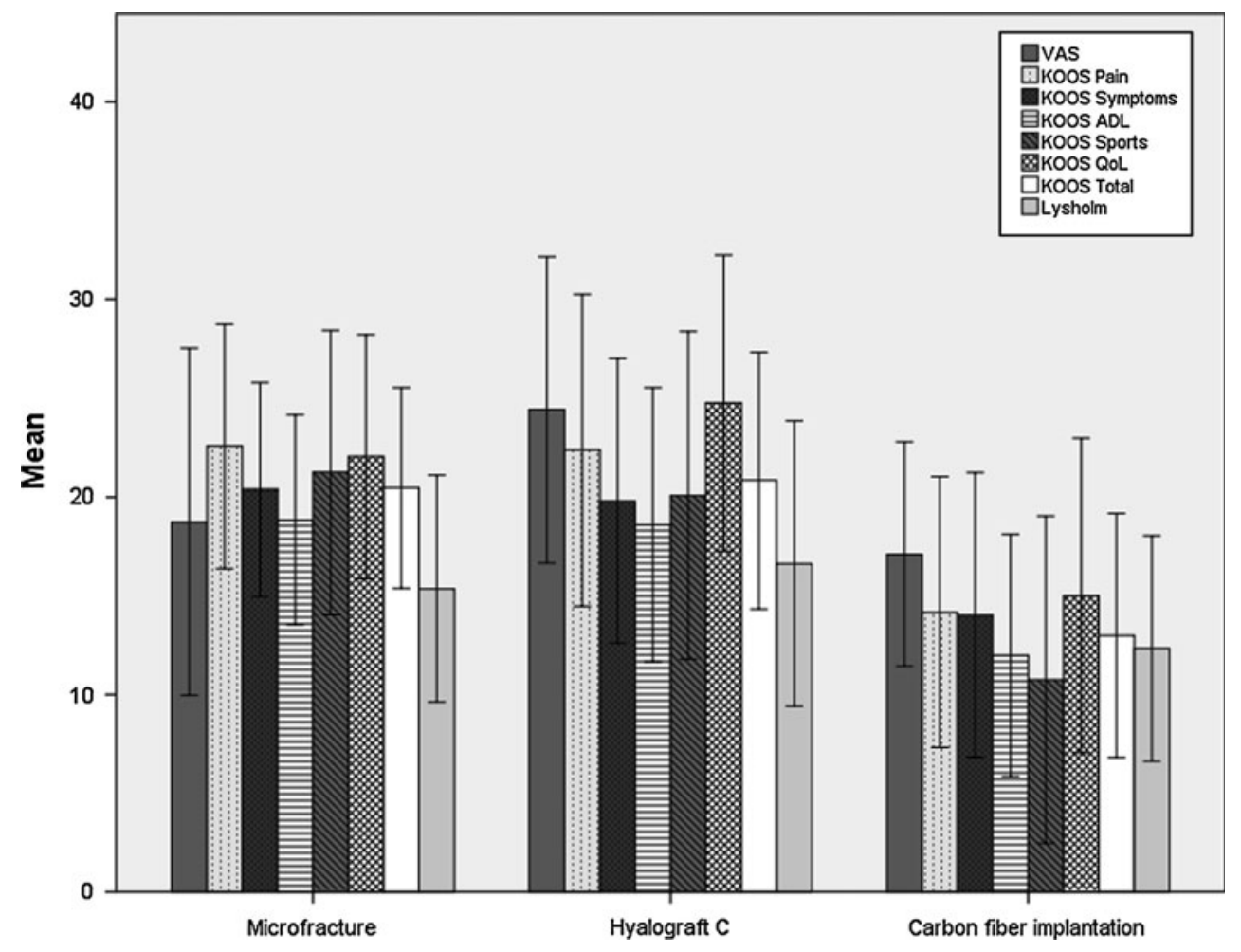

Patient age, BMI, defect cause and defect size did not seem to influence clinical outcome (n.s.). Patellar and medial lesions did not significantly differ in outcome scores compared to other defect locations for any of the treatment groups (n.s.).

In the MF cohort, patients with partial (1/3) graft repairs scored 24-32 points less improvement from baseline (regression coefficient $(B)-24.0$ to -32.4 ) on KOOS Pain, Sports and QoL subdomains $(P<0.05)$, while partial graft repairs did not reduce clinical outcome in the carbon-fiber group (n.s.).

For Hyalograft C, patients with prior ACL reconstruction had reduced improvement from baseline compared to patients without prior ACL reconstruction. (VAS $B-20.6$, overall KOOS $B-13.4$, Lysholm $B-19.8, \quad P=$ 0.006-0.042). In all patients, single defects scored 13.0, 8.4 and 8.1 points higher on KOOS Sports and QoL and Lysholm scale respectively when compared to multiple defects $(P<0.05)$.

\section{Failures}

In both the MF and Hyalograft $\mathrm{C}$ cohort there were 8 failures while there were 7 failures in the carbon-fiber group. (Table 1) Of all failures $91 \%$ occurred within 2 -years and $35 \%$ within 1-year. Patients with prior cartilage 
repair treated with MF were more likely to fail (Odds Ratio $20.5,95 \%$ confidence interval 3.4-33.2, $P=0.003$ ).

\section{Discussion}

The most important finding of the present study was that excellent clinical outcome was obtained using the patient profiling strategies of one experienced cartilage surgeon (MB) in a heterogenic population with chondral/osteochondral as well as early osteoarhtritic lesions. As such, it supports the use of the predefined treatment algorithm in a clinical environment (Fig. 1).

Although Hyalograft $\mathrm{C}$ was generally used for larger lesions, highly statistically significant clinical improvement after 3-years was achieved for both the MF and Hyalograft $\mathrm{C}$ cohorts. (Table 2) This high clinical improvement is similar to 3-year results from randomized and non-randomized studies of patients treated with cartilage repair [21, 26, 31, 43]. As pain relief was considered one of the primary goals of treatment, the statistically significant improvement $(P<0.001)$ on the VAS and KOOS pain subscale for each separate group (Table 2) further underlines the effectiveness of the current profiling strategies.

Even though Hyalograft $\mathrm{C}$ was used more often in active patients, the improvement of the KOOS sports subscale was comparable with MF after 3 years. However, long-term results might be more indicative for these patients as Hyalograft $\mathrm{C}$ has been found to have similar clinical and sports related outcome compared to MF after 2-years while achieving a superior clinical (sport related) outcome after 5-years [23]. The higher histomorphometric and histologic scores previously demonstrated in ACI compared to MF, in addition to a higher and more durable return to sports found in athletes, further support our treatment algorithm, in which Hyalograft $\mathrm{C}$ is preferred for more active patients [30, 44].

In a prospective case series, Filardo et al. [15] found second-generation ACI to achieve a lower clinical improvement if patients underwent previous surgeries such as menisectomy, ACL reconstruction, MF or mosaicplasty. This was corroborated in our Hyalograft $\mathrm{C}$ cohort, where patients with a prior ACL reconstruction exhibited a significantly lower clinical improvement from baseline. One explanation could be a disturbed joint homeostasis, that is to say that remaining instability and/or inflammation may disturb cartilage regeneration [42]. Moreover, the previously illustrated increased odds ratio of cartilage degradation after ACL rupture might continue even after reconstruction [17]. This emphasises the need for further research aiming at improving clinical outcome of patients with ACL ruptures and (subsequent) cartilage damage. Similarly to Filardo, Minas et al. [28] showed an increased failure rate of first generation ACI after marrow stimulating techniques. Although we did find a higher failure rate for $\mathrm{MF}$ as second line treatment, this did not occur in the Hyalograft $\mathrm{C}$ and carbon-fiber group. In the above-mentioned reports, a predefined treatment algorithm could not be identified. In addition, Filardo et al. [30] applied cartilage repair by surgeons in different centres. Therefore, careful patient selection and treatment by one senior surgeon following a predefined treatment algorithm, may improve treatment results. This approach could explain the superior clinical outcome we achieved for patients receiving second line cartilage repair.

In the current study, carbon-fiber scaffold implantation resulted in overall lower clinical improvement than the other two cohorts. However, carbon-fiber scaffolfds were used for a separate cohort with early osteoarthritic lesions and demonstrated a high statistically significant improvement in the VAS, KOOS Pain and Lysholm score $(P<0.001)$. Surprisingly, Nehrer et al. [32] did not find a significant improvement in Lysholm for a similar salvage group with Hyalograft $\mathrm{C}$ after 3-years. Taking the above into account, this study demonstrates that carbon-fibers are useful for salvage repair and supports the treatment of this patient category.

MF and carbon-fiber implantation were also used for partial graft repair. As MF resulted in a significantly reduced clinical improvement in these patients, carbonfibers seem to be a better option for this group as well. Nevertheless, further studies are needed to correctly identify risk factors for partial failures and improve the clinical outcome, as evidence for treatment of this challenging group is lacking in current literature.

With regard to the patient characteristics, patient age did not influence clinical outcome. This finding might be attributable to the careful treatment selection of the surgeon (MB) as older patients are more likely to have early osteoarthritic lesions and receive carbon-fiber implants. However, as no affect of age was found after correcting for treatment type, the previously illustrated influence of this variable should be considered together with other characteristics such as (sports) activity and overall health as well [12, 18, 21, 24, $25,34]$. Moreover, our findings are similar to a 2-year followup study showing no difference in clinical outcome after ACI for patients 40 years and older compared to younger patients [34]. In addition, good clinical results have recently been demonstrated after 2- to 5-years in patients 40 years and older after second-generation ACI [22].

In recent years, medial as well as lateral lesions have been shown to have better clinical outcome while patellar lesions have been reported to be more challenging to repair, possibly due to greater biomechanical shearing forces [12, 25, 36, 37]. However, when comparing medial and patellar lesions to other sites, we found no statistically significant difference in outcome scores. This is in 
accordance with a previous study demonstrating similar statistically significant $(P<0.001)$ improvement in clinical outcome after treatment of patellofemoral lesions (mean size $4.7 \mathrm{~cm}^{2}$ ) treated with Hyalograft C [16].

Regardless of treatment type, multiple defects resulted in lower clinical improvement compared to single defects. Similarly, Solheim et al. [46] found inferior clinical outcome for MF of multiple versus single defects. Although these patients seem to benefit of cartilage repair as shown by improved outcome scores, multiple defects should be regarded as a separate, more difficult patient population.

Limitations of this study could be that it lacks randomization, includes different locations in the knee with a variety of defect etiologies and did not include a control group. However, we stress that the primary goal of this observational prospective study was not to demonstrate superiority of one particular treatment but to evaluate the clinical outcome of a heterogenic patient population after treatment of one experienced surgeon (MB) according to a predefined selection algorithm. Moreover, the indications of the cartilage repair procedures do not overlap, which may emphasize why randomization in this patient category is difficult and why previous randomized trials do not include all patients suitable for cartilage repair [14, 20]. The strengths of this study lie in the treatment of a relatively large group of patients and the inclusion of a wide range of patients suitable for cartilage repair in different cohorts. Unlike most cartilage repair reports, where data are published based on multi-surgeon and/or centre studies, this study focused on a single senior surgeon in one specialized cartilage repair centre.

\section{Conclusion}

To the best of our knowledge, this is the first assessment of the treatment strategies used by one experienced cartilage surgeon based on lesion and patient characteristics. We provide a treatment algorithm with pain, lesion type, defect size and patient activity as indicators for treatment selection (Fig. 1). Our data suggest Hyalograft $\mathrm{C}$ to be a good second line treatment option and support the treatment of early osteoarthritic lesions. The treatment algorithm and new insights of this single-surgeon study could be used for patient profiling in a day-to-day clinical environment.

Conflict of interest The authors declare that they have no conflict of interest.

Open Access This article is distributed under the terms of the Creative Commons Attribution Noncommercial License which permits any noncommercial use, distribution, and reproduction in any medium, provided the original author(s) and source are credited.

\section{References}

1. Basad E, Ishaque B, Bachmann G, Sturz H, Steinmeyer J (2010) Matrix-induced autologous chondrocyte implantation versus microfracture in the treatment of cartilage defects of the knee: a 2-year randomised study. Knee Surg Sports Traumatol Arthrosc 18:519-527

2. Bekkers JE, de Windt TS, Raijmakers NJ, Dhert WJ, Saris DB (2009) Validation of the Knee Injury and Osteoarthritis Outcome Score (KOOS) for the treatment of focal cartilage lesions. Osteoarthr Cartil 17:1434-1439

3. Bekkers JE, Inklaar M, Saris DB (2009) Treatment selection in articular cartilage lesions of the knee: a systematic review. Am J Sports Med 37(Suppl 1):148S-155S

4. Benke G, Strzelczyk P, Kowalski M, Swiader P (2001) The use of carbon fibers to restore cartilage defects in the knee. Ortop Traumatol Rehabil 3:227-229

5. Brittberg M (2008) Autologous chondrocyte implantation-technique and long-term follow-up. Injury 39(Suppl 1):S40-S49

6. Brittberg M (2009) ... more bricks to the building of cartilage knowledge? Knee Surg Sports Traumatol Arthrosc 17:12751277

7. Brittberg M, Faxen E, Peterson L (1994) Carbon fiber scaffolds in the treatment of early knee osteoarthritis. A prospective 4-year followup of 37 patients. Clin Orthop Relat Res 307:155-164

8. Brittberg M, Lindahl A, Nilsson A, Ohlsson C, Isaksson O, Peterson L (1994) Treatment of deep cartilage defects in the knee with autologous chondrocyte transplantation. N Engl J Med 331:889-895

9. Brittberg M, Winalski CS (2003) Evaluation of cartilage injuries and repair. J Bone Joint Surg Am 85-A(Suppl 2):58-69

10. Chan YH (2004) Biostatistics 201: linear regression analysis. Singapore Med J 45:55-61

11. Chan YH (2004) Biostatistics 202: logistic regression analysis. Singapore Med J 45:149-153

12. de Windt TS, Bekkers JE, Creemers LB, Dhert WJ, Saris DB (2009) Patient profiling in cartilage regeneration: prognostic factors determining success of treatment for cartilage defects. Am J Sports Med 37(Suppl 1):58S-62S

13. Durbin J, Watson GS (1950) Testing for serial correlation in least squares regression I. Biometrika 37:409-428

14. Engen CN, Engebretsen L, Aroen A (2010) Knee cartilage defect patients enrolled in randomized controlled trials are not representative of patients in orthopedic practice. Cartilage 1:312319

15. Filardo G, Kon E, Di MA, Iacono F, Marcacci M (2011) Arthroscopic second-generation autologous chondrocyte implantation: a prospective 7-year follow-up study. Am J Sports Med 39:2153-2160

16. Gobbi A, Kon E, Berruto M, Filardo G, Delcogliano M, Boldrini L, Bathan L, Marcacci M (2009) Patellofemoral full-thickness chondral defects treated with second-generation autologous chondrocyte implantation: results at 5 years' follow-up. Am J Sports Med 37:1083-1092

17. Granan LP, Bahr R, Lie SA, Engebretsen L (2009) Timing of anterior cruciate ligament reconstructive surgery and risk of cartilage lesions and meniscal tears: a cohort study based on the Norwegian National Knee Ligament Registry. Am J Sports Med 37:955-961

18. Gudas R, Simonaityte R, Cekanauskas E, Tamosiunas R (2009) A prospective, randomized clinical study of osteochondral autologous transplantation versus microfracture for the treatment of osteochondritis dissecans in the knee joint in children. J Pediatr Orthop 29:741-748 
19. Harris JD, Brophy RH, Siston RA, Flanigan DC (2010) Treatment of chondral defects in the athlete's knee. Arthroscopy 26:841-852

20. Jakobsen RB, Engebretsen L, Slauterbeck JR (2005) An analysis of the quality of cartilage repair studies. J Bone Joint Surg Am 87:2232-2239

21. Knutsen G, Engebretsen L, Ludvigsen TC, Drogset JO, Grontvedt T, Solheim E, Strand T, Roberts S, Isaksen V, Johansen O (2004) Autologous chondrocyte implantation compared with microfracture in the knee. A randomized trial. J Bone Joint Surg Am 86-A:455-464

22. Kon E, Filardo G, Condello V, Collarile M, Di MA, Zorzi C, Marcacci M (2011) Second-generation autologous chondrocyte implantation: results in patients older than 40 years. Am J Sports Med 39:1668-1675

23. Kon E, Gobbi A, Filardo G, Delcogliano M, Zaffagnini S, Marcacci M (2009) Arthroscopic second-generation autologous chondrocyte implantation compared with microfracture for chondral lesions of the knee: prospective nonrandomized study at 5 years. Am J Sports Med 37:33-41

24. Kreuz PC, Erggelet C, Steinwachs MR, Krause SJ, Lahm A, Niemeyer P, Ghanem N, Uhl M, Sudkamp N (2006) Is microfracture of chondral defects in the knee associated with different results in patients aged 40 years or younger? Arthroscopy 22:1180-1186

25. Krishnan SP, Skinner JA, Bartlett W, Carrington RW, Flanagan AM, Briggs TW, Bentley G (2006) Who is the ideal candidate for autologous chondrocyte implantation? J Bone Joint Surg Br 88:61-64

26. Marcacci M, Berruto M, Brocchetta D, Delcogliano A, Ghinelli D, Gobbi A, Kon E, Pederzini L, Rosa D, Sacchetti GL, Stefani G, Zanasi S (2005) Articular cartilage engineering with Hyalograft C: 3-year clinical results. Clin Orthop Relat Res 435:96-105

27. Meister K, Cobb A, Bentley G (1998) Treatment of painful articular cartilage defects of the patella by carbon-fibre implants. J Bone Joint Surg Br 80:965-970

28. Minas T, Gomoll AH, Rosenberger R, Royce RO, Bryant T (2009) Increased failure rate of autologous chondrocyte implantation after previous treatment with marrow stimulation techniques. Am J Sports Med 37:902-908

29. Minas T, Gomoll AH, Solhpour S, Rosenberger R, Probst C, Bryant T (2010) Autologous chondrocyte implantation for joint preservation in patients with early osteoarthritis. Clin Orthop Relat Res 468:147-157

30. Mithoefer K, Hambly K, Della VS, Silvers H, Mandelbaum BR (2009) Return to sports participation after articular cartilage repair in the knee: scientific evidence. Am J Sports Med 37(Suppl 1): $167 \mathrm{~S}-176 \mathrm{~S}$

31. Nehrer S, Domayer S, Dorotka R, Schatz K, Bindreiter U, Kotz R (2006) Three-year clinical outcome after chondrocyte transplantation using a hyaluronan matrix for cartilage repair. Eur J Radiol $57: 3-8$

32. Nehrer S, Dorotka R, Domayer S, Stelzeneder D, Kotz R (2009) Treatment of full-thickness chondral defects with hyalograft $\mathrm{C}$ in the knee: a prospective clinical case series with 2 to 7 years' follow-up. Am J Sports Med 37(Suppl 1):81S-87S

33. Nicholson P, Mulcahy D, Curtin B, McElwain JP (1998) Role of carbon fibre implants in osteochondral defects of the knee. Ir J Med Sci 167:86-88

34. Niemeyer P, Kostler W, Salzmann GM, Lenz P, Kreuz PC, Sudkamp NP (2010) Autologous chondrocyte implantation for treatment of focal cartilage defects in patients age 40 years and older: a matched-pair analysis with 2-year follow-up. Am J Sports Med 38:2410-2416

35. Niemeyer P, Pestka JM, Erggelet C, Steinwachs M, Salzmann GM, Sudkamp NP (2011) Comparison of arthroscopic and open assessment of size and grade of cartilage defects of the knee. Arthroscopy 27:46-51

36. Niemeyer P, Pestka JM, Kreuz PC, Erggelet C, Schmal H, Suedkamp NP, Steinwachs M (2008) Characteristic complications after autologous chondrocyte implantation for cartilage defects of the knee joint. Am J Sports Med 36:2091-2099

37. Niemeyer P, Steinwachs M, Erggelet C, Kreuz PC, Kraft N, Kostler W, Mehlhorn A, Sudkamp NP (2008) Autologous chondrocyte implantation for the treatment of retropatellar cartilage defects: clinical results referred to defect localisation. Arch Orthop Trauma Surg 128:1223-1231

38. Pavesio A, Abatangelo G, Borrione A, Brocchetta D, Hollander AP, Kon E, Torasso F, Zanasi S, Marcacci M (2003) Hyaluronanbased scaffolds (Hyalograft $\mathrm{C}$ ) in the treatment of knee cartilage defects: preliminary clinical findings. Novartis Found Symp 249:203-217

39. Peterson L, Minas T, Brittberg M, Nilsson A, Sjogren-Jansson E, Lindahl A (2000) Two- to 9-year outcome after autologous chondrocyte transplantation of the knee. Clin Orthop Relat Res 374:212-234

40. Peterson L, Vasiliadis HS, Brittberg M, Lindahl A (2010) Autologous chondrocyte implantation: a long-term follow-up. Am J Sports Med 38:1117-1124

41. Roos EM, Roos HP, Lohmander LS, Ekdahl C, Beynnon BD (1998) Knee injury and osteoarthritis outcome score (KOOS) development of a self-administered outcome measure. J Orthop Sports Phys Ther 28:88-96

42. Saris DB, Dhert WJ, Verbout AJ (2003) Joint homeostasis. The discrepancy between old and fresh defects in cartilage repair. J Bone Joint Surg Br 85:1067-1076

43. Saris DB, Vanlauwe J, Victor J, Almqvist KF, Verdonk R, Bellemans J, Luyten FP (2009) Treatment of symptomatic cartilage defects of the knee: characterized chondrocyte implantation results in better clinical outcome at 36 months in a randomized trial compared to microfracture. Am J Sports Med 37(Suppl 1): $10 \mathrm{~S}-19 \mathrm{~S}$

44. Saris DB, Vanlauwe J, Victor J, Haspl M, Bohnsack M, Fortems Y, Vandekerckhove B, Almqvist KF, Claes T, Handelberg F, Lagae K, van der Bouwhede J, Vandenneucker H, Yang KG, Jelic M, Verdonk R, Veulemans N, Bellemans J, Luyten FP (2008) Characterized chondrocyte implantation results in better structural repair when treating symptomatic cartilage defects of the knee in a randomized controlled trial versus microfracture. Am J Sports Med 36:235-246

45. Smith HJ, Richardson JB, Tennant A (2009) Modification and validation of the Lysholm Knee Scale to assess articular cartilage damage. Osteoarthr Cartil 17:53-58

46. Solheim E, Oyen J, Hegna J, Austgulen OK, Harlem T, Strand T (2010) Microfracture treatment of single or multiple articular cartilage defects of the knee: a 5-year median follow-up of 110 patients. Knee Surg Sports Traumatol Arthrosc 18:504-508

47. Steadman JR, Briggs KK, Rodrigo JJ, Kocher MS, Gill TJ, Rodkey WG (2003) Outcomes of microfracture for traumatic chondral defects of the knee: average 11-year follow-up. Arthroscopy 19:477-484

48. Van AD, Staes F, Van CD, Vanlauwe J, Bellemans J, Saris DB, Luyten FP (2010) Autologous chondrocyte implantation versus microfracture for knee cartilage injury: a prospective randomized trial, with 2-year follow-up. Knee Surg Sports Traumatol Arthrosc 18:486-495

49. Zaslav K, Cole B, Brewster R, DeBerardino T, Farr J, Fowler P, Nissen C (2009) A prospective study of autologous chondrocyte implantation in patients with failed prior treatment for articular cartilage defect of the knee: results of the Study of the Treatment of Articular Repair (STAR) clinical trial. Am J Sports Med $37: 42-55$ 